\title{
UM ESTUDO DAS MOTIVAÇÕES PARA IMPLANTAÇÃO DE PROGRAMAS DE LOGÍSTICA REVERSA DE MICROCOMPUTADORES
}

\author{
1- Ezequiel Ferreira dos Santos \\ Universidade Nove de Julho - UNINOVE \\ efsantos@uninove.br
}

\author{
2- Maria Tereza Saraiva de Souza \\ Universidade Nove de Julho - UNINOVE \\ mtereza@uninove.br
}

Diego Maganhotto Coraiola - Editor

\section{RESUMO}

O objetivo deste estudo é verificar os fatores determinantes que motivaram a implantação e manutenção de programas de logística reversa para o gerenciamento de resíduos de microcomputadores pósconsumo. São escassas as pesquisas que avaliam o impacto sobre o meio ambiente provocado pelo descarte inadequado dos microcomputadores e principalmente as alternativas sustentáveis para a mitigação destes impactos. A pesquisa é de caráter exploratório e qualitativo, utilizando estratégia de estudo de casos múltiplos. As organizações pesquisadas são fabricantes de microcomputadores, sendo uma nacional e outra multinacional, ambas de grande porte. As fontes de evidência utilizadas foram entrevistas semi-estruturadas, registro em arquivos, pesquisa documental e observação direta. Os resultados da pesquisa mostram que os principais fatores que determinaram a implantação e manutenção do processo de logística reversa nas empresas pesquisadas foram: o impacto ambiental, os recursos escassos, a legislação, a imagem institucional, o sistema de gestão ambiental e envolvimento da alta administração.

Palavras-Chave

Gestão Ambiental; Meio Ambiente; Impacto Ambiental; Logística Reversa; Resíduos Sólidos; Reciclagem.

\section{ABSTRACT}

The goal of this study is to verify the determining factors which motivated the deployment and maintenance of reverse logistics programs for microcomputers waste management post-consumption. Are few searches that assess the impact on the environment caused by disposing of microcomputers and especially sustainable alternatives to mitigate these impacts. The search is qualitative and exploratory nature, using case study strategy. Organizations surveyed are manufacturers of microcomputers, being a national and other multinational, both large businesses. Evidence used sources were semi-structured interviews, log files, direct research and observation. The search results show that the main factors that have led to the deployment and maintenance of reverse logistics process in companies surveyed were: environmental impact, the scarce resources, legislation, institutional image, the environmental management system and involvement of senior management.

Keywords

Environmental management; environment; environmental impact; reverse logistics; solid waste; recycling. 


\section{Introdução}

Os microcomputadores já fazem parte do dia a dia de grande número de usuário no Brasil. Em 2006, havia 22 milhões, ou seja, de cada 100 brasileiros, 10,7 contavam com a tecnologia, a média mundial era de 12,2 computadores para cada 100 pessoas. Com o câmbio favorável, a tendência de redução dos preços e da rápida obsolescência de tais equipamentos, a quantidade per capita no Brasil, em poucos anos, irá superar a média mundial, como mostra a Tabela 1.

Tabela 1 - Produção anual de equipamentos de informática no Brasil
\begin{tabular}{|l|c|c|c|c|c|c|}
\hline Segmentos & 2004 & 2005 & 2006 & 2007 & 2008 & 2009 \\
\hline Doméstico & 5.234 .347 & 6.406 .036 & 8.662 .000 & 11.279 .000 & 14.083 .200 & 17.046 .000 \\
\hline Corporativo & 11.143 .630 & 11.900 .529 & 13.614 .000 & 15.540 .500 & 17.365 .000 & 19.043 .750 \\
\hline Servidores & 274.850 & 298.210 & 325.384 & 345.490 & 364.980 & 378.698 \\
\hline Total & 16.652 .827 & 18.604 .775 & 22.601 .384 & 27.164 .990 & 31.813 .180 & 36.468 .448 \\
\hline
\end{tabular}

Fonte: IT Data Consultoria, 2006.

Assim como o consumo disseminado de computadores é recente, o surgimento de resíduos tecnológicos é também um fato novo. No início da década de 1980, quando começou o processo de produção e uso dos computadores pessoais, não havia preocupações com a destinação dos resíduos pós-consumo. Desde então, milhões de microcomputadores se tornaram obsoletos causando problemas ao meio ambiente, em decorrência de sua destinação incorreta. Até 2004 foram descartados 315 milhões de microcomputadores em todo o mundo. Neste período, no Brasil houve o descarte de um milhão de equipamentos. Tal fato contribuiu para 0 aumento dos problemas ambientais, porque os microcomputadores obsoletos ocupam grandes espaços e muitos de seus componentes internos possuem metais tóxicos pesados que causam problemas de saúde para a população, tais como mercúrio, níquel, cádmio, arsênico e chumbo. Apesar de todos os problemas que tais substâncias causam, para agravar ainda mais a situação são incipientes as iniciativas de empresas, ONGs e governos em dimensionar os impactos e propor soluções adequadas a essa questão.

O descarte dos microcomputadores, no fim de sua vida útil, em lixões e aterros provoca um grande impacto no meio ambiente. Segundo o modelo de Matthews e Matthews (2003) dos 580 milhões de microcomputadores previstos para serem vendidos nos Estados Unidos em 2005, apenas 72 milhões de unidades seriam recicladas e 154 milhões encaminhadas para aterros sanitários.

No âmbito nacional, a única regulamentação aplicável aos microcomputadores é a Convenção da Basiléia (SECRETARIA DO MEIO AMBIENTE, 1997). Empresários e ambientalistas de 120 países, inclusive do Brasil, ratificaram a convenção que visa proibir o movimento de resíduos perigosos entre os países participantes.

Apesar de ser signatária da Convenção da Basiléia, a legislação brasileira não classifica como resíduos perigosos, os computadores em desuso, não proibindo, portanto a importação desses equipamentos. Entretanto o Decreto $\mathrm{n}^{\circ} 875$, de 19 de Julho de 1993, que ratificou os Anexos VIII e IX dessa Convenção, lista os resíduos perigosos e não perigosos respectivamente. Para cumprimento desse decreto, no caso dos microcomputadores, seria necessário criar uma estrutura para dar suporte a todas as fases que compõe uma gestão adequada desses resíduos que contemple desde a coleta até a destinação final. Essa estrutura deve levar em consideração os métodos de tratamento, a capacidade e estrutura para reciclagem e as tecnologias disponíveis e o mercado para absorver os produtos reciclados.

Muitos dos componentes dos microcomputadores podem ser reciclados ou reutilizados. Quando tais equipamentos são simplesmente descartados há uma agressão dupla ao meio ambiente, uma pelo impacto ambiental provocado pela disposição incorreta de tais resíduos e outra na perda de matérias-primas que poderiam ser incorporadas novamente ao processo produtivo como matéria-prima secundária.

Várias pesquisas indicam o crescimento dos resíduos sólidos provenientes de microcomputadores pós-consumo, entretanto há poucas pesquisas no Brasil, que abordam medidas empresariais para mitigar o impacto do lixo tecnológico no meio-ambiente, como a utilização de programas de logística reversa. A maior parte dos 
estudos nesta área está concentrada na Europa e nos Estados Unidos.

Diante do exposto, neste estudo busca-se resolver o seguinte problema de pesquisa: quais são os fatores motivadores do processo de implantação e manutenção da logística reversa no gerenciamento de resíduos de lixo tecnológico pósconsumo?

O objetivo deste estudo, portanto, é verificar as motivações organizacionais e a consequente contribuição da logística reversa para o gerenciamento de resíduos tecnológicos pósconsumo. Como decorrência do objetivo geral, os objetivos específicos a serem alcançados são os seguintes: verificar o impacto que os resíduos dos microcomputadores no Brasil provocam no meio ambiente; identificar as tecnologias disponíveis para a reciclagem ou reutilização e descarte desses equipamentos; pesquisar as principais práticas adotadas pelas empresas para o gerenciamento de resíduos tecnológicos; avaliar as dificuldades de transporte e armazenamento de microcomputadores de pós-consumo e detectar se os programas de logística reversa pós-consumo proporcionam ganhos econômicos.

\section{Referencial Teórico}

A logística reversa teve acentuada relevância a partir dos anos 1980, pela constatação dos impactos provocados por materiais e produtos descartados pós-consumo no meio ambiente. $\mathrm{Na}$ década seguinte, outros fatores, tais como a redução de ciclo de vida dos produtos, a identificação de novas oportunidades competitivas por meio da redução de custos, a defesa de imagem corporativa e de responsabilidade social ou ainda o aumento do rigor de legislação contribuíram para destacar ainda mais a importância da implantação desse programa.

Segundo Stock (1998), sob a perspectiva logística do negócio, esse termo se refere ao papel da logística na devolução de produtos, redução, reutilização e reciclagem de materiais, tratamento de resíduos, substituição, conserto ou remanufatura. Do ponto de vista de engenharia, a logística reversa é um modelo de negócio sistêmico que aplica os melhores métodos de engenharia e administração logística na empresa para a fechar de forma lucrativa o ciclo do supply chain.

A Figura 1 mostra a sequência entre a extração da matéria-prima (materiais novos), sua utilização na produção de bens (suprimento e produção) e a sua venda ao cliente final por meio dos canais de distribuição. A logística reversa dos produtos pósconsumo teria como finalidade a utilização de peças, componentes e materiais do pós-consumo como insumos no início da cadeia de produção, reduzindo assim os impactos ambientais.

Figura 1 - Fluxo da logística reversa

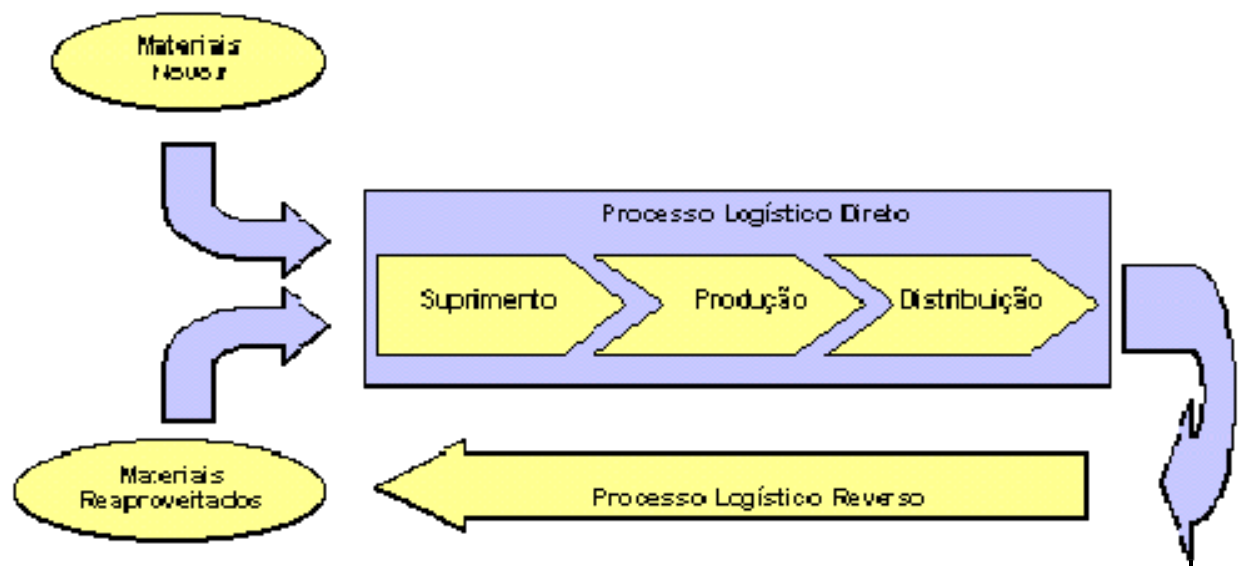

Fonte: LACERDA, 2002.

Para Rogers e Tibben-Lembke (1999), logística reversa é o "[...] o processo de planejamento, implementação e controle do fluxo de matérias primas, estoque em processo e produtos acabados, incluindo todo o fluxo de informação, do ponto de consumo ao ponto de origem, com o objetivo de recapturar valor ou realizar um descarte adequado". Neste contexto, esse programa pode aumentar tanto o valor do produto quanto a rentabilidade da empresa. Para os autores, logística reversa é:

[...] o processo de movimentação de produtos da sua típica destinação final para outro ponto, com o propósito de capturar valor ou enviá-lo para destinação segura. As tarefas da logística reversa incluem processar a mercadoria retornada por razões como dano, sazonalidade, reposição, recall ou excesso de inventário; reciclar materiais de embalagem e reutilizar containers; recondicionar, re- 
manufaturar e reformar produtos; dar disposição a equipamentos obsoletos; programa para materiais perigosos; recuperação de ativos (ROGERS; TIBBENLEMBKE, 1999).

As principais razões que levam as empresas a atuar na área de Logística Reversa, de acordo com o grupo RevLog (2009), são as seguintes: a legislação ambiental, que força as empresas a retornarem seus produtos e cuidar do tratamento necessário; benefícios econômicos do uso de produtos que retornam ao processo de produção, ao invés dos altos custos do correto descarte do lixo; e a crescente conscientização ambiental dos consumidores.

Rogers e Tibben-Lembke (1999) apontam os motivos estratégicos da logística reversa: razões competitivas com a diferenciação do serviço; limpeza do canal de distribuição; e recaptura de valor e recuperação de ativos, a Figura 2 mostra a interseção entre a logística convencional e a logística com motivos ambientais.

\section{Figura 2 - Logística Reversa X Logística Ambiental}

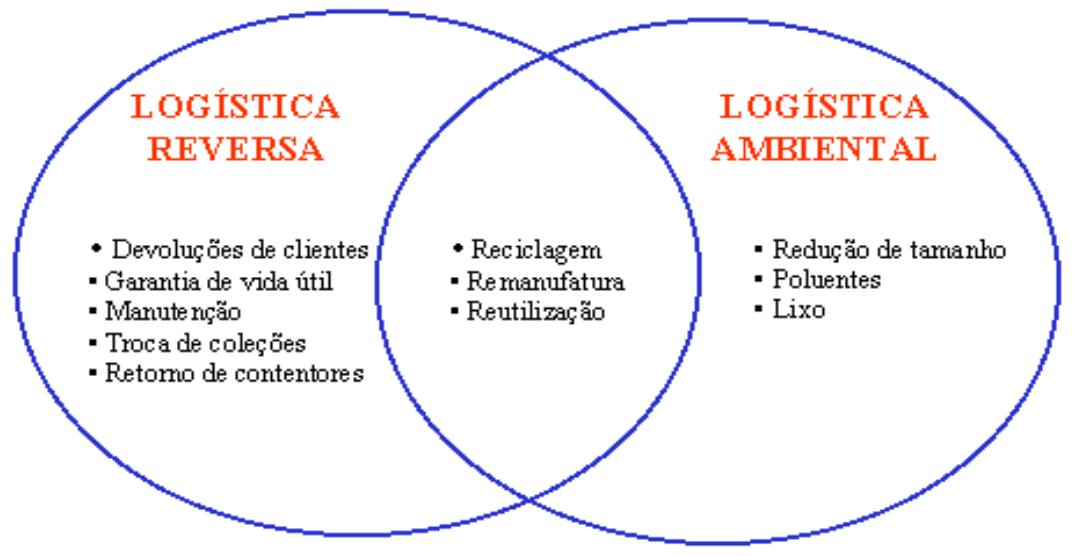

Fonte: Rogers; Tibben-Lembke (1999).

Logística reversa de pós-consumo trata do fluxo físico e das informações correspondentes aos bens de consumo descartados pela sociedade, em fim de vida útil ou usados com possibilidade de utilização, além dos resíduos industriais, que retornam ao ciclo de negócios ou ao ciclo produtivo pelos canais de distribuição reversos específicos.

Para produtos de "fim de vida útil", a logística reversa poderá atuar no canal reverso de desmontagem e reciclagem industrial. Sendo desmontados na área de 'desmanche', seus componentes poderão ser aproveitados ou remanufaturados, retornando ao mercado secundário ou à própria indústria para serem reutilizados. Caso não apresentem as condições mencionadas| acima, serão destinados aos aterros sanitários, lixões e incineração com recuperação energética, como mostra a Figura 3.

Figura 3 - Logística Reversa e reutilização/reciclagem
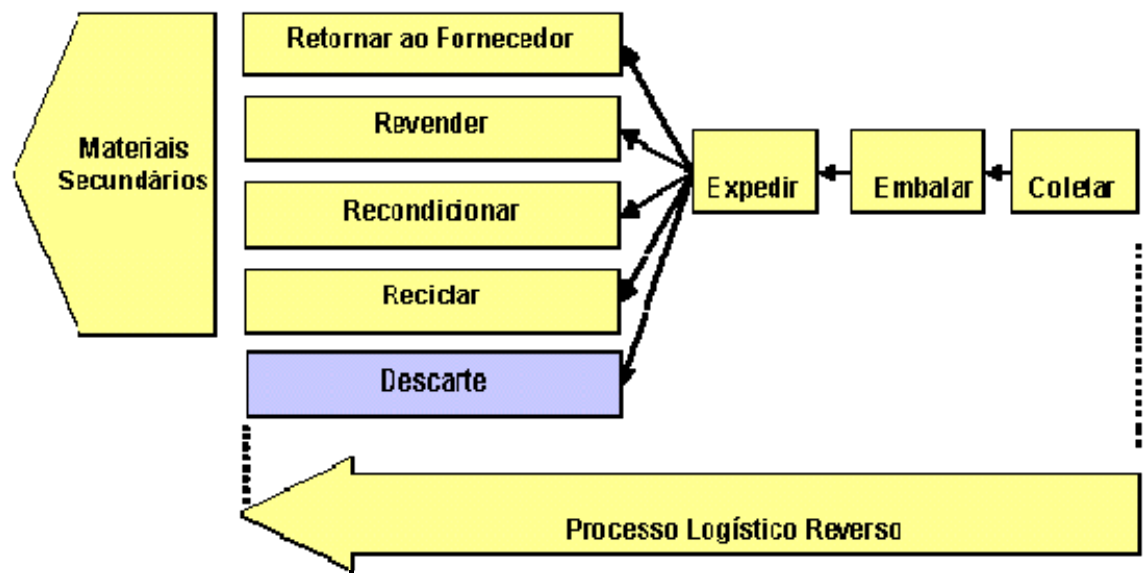

Fonte: Rogers; Tibben-Lembke (1999). 
Do ponto de vista logístico, a vida de um produto não termina com a sua entrega ao cliente. Produtos se tornam obsoletos, danificados, ou não funcionam, e devem retornar ao seu ponto de origem para serem adequadamente descartados, reparados ou reaproveitados.

A observação dos hábitos empresariais no Brasil tem revelado avanços importantes na implementação de logística reversa, em consequência do crescimento dos volumes transacionados nesses últimos anos, da difusão de suas principais idéias, da melhor compreensão de seus objetivos e possibilidades estratégicas e das oportunidades empresariais para os agentes das cadeias de suprimentos. Seguindo a mesma linha européia e americana, observa-se no Brasil o aparecimento, no final da década de 1990, dos primeiros artigos em revistas especializadas e os primeiros estudos acadêmicos sobre esse tema (LEITE, 2004).

Os dados da pesquisa realizada pela CoppeadUFRJ sobre operadores logísticos comprovam o crescimento desse interesse no Brasil ao revelar, entre outros elementos dos serviços logísticos oferecidos no mercado em 2003, que $82 \%$ dos operadores logísticos que atuam no Brasil oferecem o serviço de logística reversa, com um crescimento de oferta de $47 \%$ entre 2000 e 2003. Esse crescimento e interesse não se revelam homogêneos em todos os setores empresariais, em razão dos diferentes níveis de impacto causados pelo retorno de produtos e materiais ao ciclo de negócios e produtivos (FLEURY, 2000; LEITE, 2003).

Pesquisas conduzidas no País desde 2002 demonstram que há uma melhor compreensão e conhecimento de logística reversa nos últimos anos. Um reflexo disso é o crescimento na implementação de programas que buscam aperfeiçoar as cadeias reversas tradicionais e implementar novas cadeias reversas. No entanto, constata-se que as empresas em geral ainda tem pouco acesso a essa informação, em decorrência dos poucos trabalhos científicos existentes nesta área no Brasil (LEITE, 2005).

\subsection{Impacto Ambiental dos Microcomputadores}

Recentemente várias peças de microcomputadores foram lançadas no mercado como Restriction of Certain Hazardous Substances (RoHS) que significa Restrição de Certas Substâncias Perigosas. O RoHS é uma legislação européia que proíbe o uso de substâncias perigosas em processos de fabricação dos seguintes produtos: cádmio $(\mathrm{Cd})$, mercúrio $(\mathrm{Hg})$, cromo hexavalente $(\mathrm{Cr}(\mathrm{VI}))$, bifenilos polibromados (PBBs), éteres difenil-polibromados (PBDEs) e chumbo $(\mathrm{Pb})$. Esta legislação entrou em vigor no dia $1^{\circ}$ de julho de 2006 e a partir desta data nenhum produto que tenha essas substâncias pode ser vendido na Europa.

No continente europeu começou a vigorar em 13 de Agosto de 2005 outra diretiva que trata da reciclagem de produtos eletroeletrônicos, chamada Waste from Electrical and Electronic Equipment (WEEE), Lixo Vindo de Produtos Eletro-Eletrônicos. Esta diretiva determina o princípio do PoluidorPagador, em que os produtores e importadores de produtos eletroeletrônicos (até $1.000 \mathrm{v}$ de corrente alternada e 1.500v de corrente contínua) são os responsáveis pelo ciclo de vida de seus produtos, arcando com os custos de coleta seletiva, transporte, tratamento, reciclagem, além de fazer uma provisão para fim do ciclo de vida. Além disso, se responsabilizam pelo custo do "lixo histórico", fornecem informações às recicladoras sobre produtos, conteúdo e tratamento, dando prioridade ao reuso dos equipamentos, estabelecem rigor nas penalidades impostas pelos países-membros e promovem o ecodesign. Para as áreas de Tecnologia de Informação e Telecomunicações foram estabelecido índices de $75 \%$ de recuperação e $65 \%$ de reciclagem dos equipamentos.

As substâncias nocivas, alvo da diretriz RoHS, são agressivas à saúde humana quando descartadas de forma incorreta e combinadas com agentes externos que promovem a degradação das partes que contém esses componentes. A ação da chuva ácida em uma placa de circuito impresso danificada e descartada inadequadamente no meio ambiente sequestra o chumbo do restante do material e atinge o lençol freático, contaminando as águas superficiais. Essa água contaminada pode ser consumida por animais e o próprio homem. $\mathrm{O}$ chumbo, especificamente, provoca doenças cerebrais (saturnismo), normalmente irreversíveis. O mercúrio é utilizado em baterias, sensores, relés e chaves causam danos ao cérebro e tem características cumulativas. O cádmio, em pigmentos de pintura, galvanoplastia, solda, acumuladores e estabilizadores de PVC, cancerígeno, ataca os rins e causa desmineralização óssea. O cromo VI, usado em tratamento anticorrosivo e na blindagem elétrica de alguns componentes, facilmente absorvido pelas células, tem efeito alérgico e tóxico. PBB's e PBDE's são produtos retardadores de chama adicionados aos polímeros dos materiais elétricos e eletrônicos, cancerígenos e neurotóxico, são solúveis, biocumulativos e resistem à decomposição. 
O primeiro país a adotar a tecnologia "lead free" (solda sem chumbo) foi o Japão em 2004, e a partir de Julho de 2006, os países europeus, a China e alguns estados da América do Norte (EUA) também adotaram este programa, portanto não são admitidos a comercialização de quaisquer produtos eletroeletrônicos que contenham chumbo acima de $0,1 \%$ ou 1.000 PPM em peso de cada item eletrônico.

O chumbo é o metal mais presente em módulos eletrônicos e participa com o teor de $37 \%$ em peso da liga de solda utilizada nas soldagens das placas eletrônicas. O chumbo foi substituído por dois outros metais, prata e cobre na seguinte proporção: $95,5 \%$ de estanho, $3,0 \%$ de prata e $0,5 \%$ de cobre.

O problema é que a solda tradicional é composta de $60 \%$ de estanho (Sn) e $40 \%$ de chumbo $(\mathrm{Pb})$, o que obrigará os fabricantes de equipamentos eletrônicos a buscar outros materiais para fazer a solda. A prata, o cobre e o bismuto são comumente usados como substitutos do chumbo. Claro que além da solda todas as outras partes do equipamento eletrônico - como componentes e a placa de circuito impresso (PCB) - não deve ter nenhum dos seis materiais banidos para serem considerados "de acordo com o RoHS" e poderem ser vendidos na Europa.

\subsection{Modelo Conceitual}

Segundo Miles e Huberman (1994), o modelo conceitual explica graficamente os fatores chave, construtos ou variáveis do estudo, e identifica as possíveis relações entre eles.

Essa pesquisa parte do pressuposto que as empresas estão desenvolvendo programas de logística reversa para coletar e dar destino aos microcomputadores pós-consumo pelas demandas da legislação, impactos ambientais, custos e imagem organizacional. O modelo apresentado na Figura 4 foi utilizado como parâmetro para a análise dos dados obtidos na pesquisa e a discussão dos seus resultados. As setas do modelo foram enumeradas de 1 a 12 para facilitar a identificação.

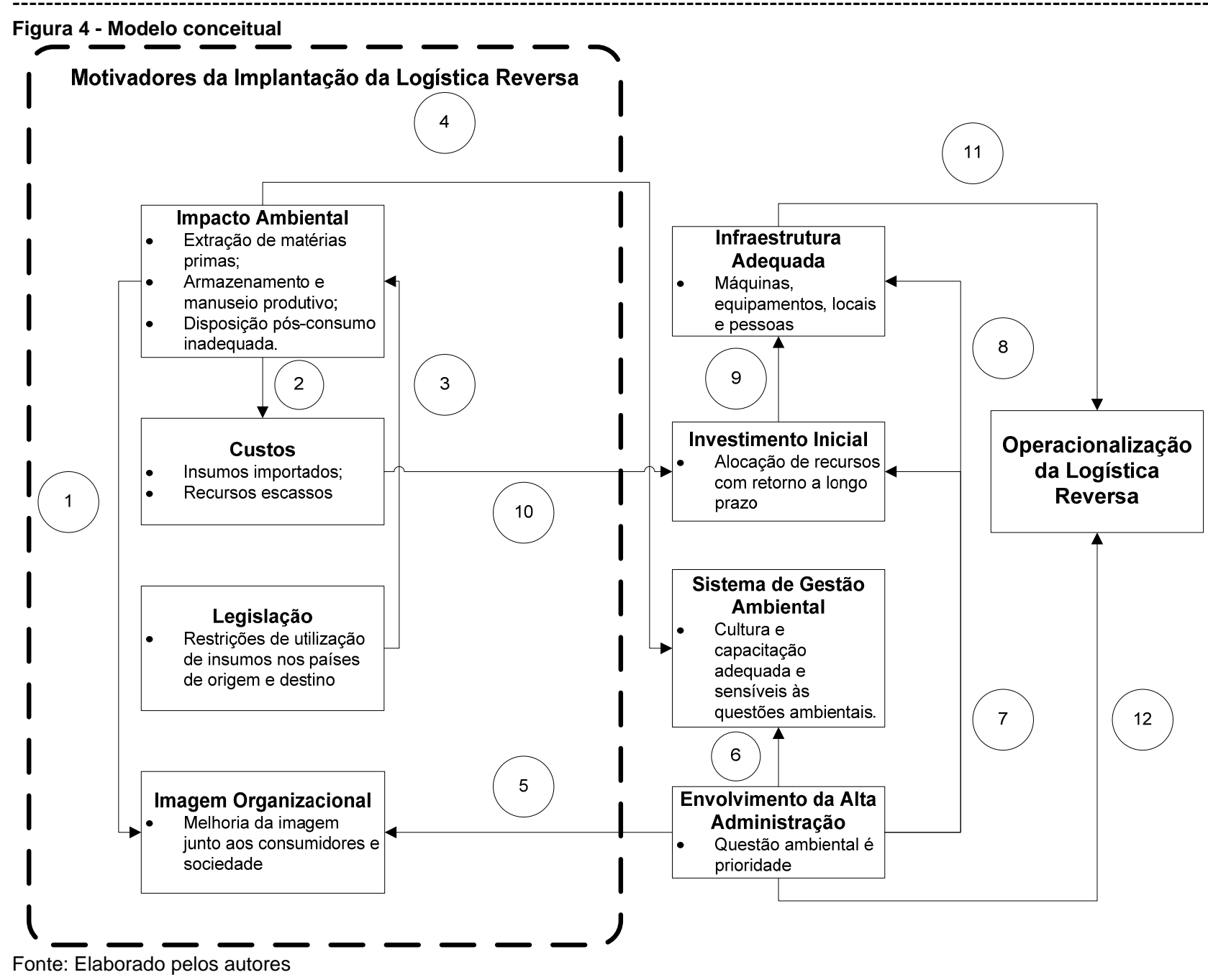


Esse estudo parte do pressuposto de que para implantar a Logística Reversa para os microcomputadores devem existir fatores motivadores e facilitadores para sua operacionalização. Os principais são os seguintes:

- Impacto ambiental causado na extração das matérias-primas, no seu transporte, armazenamento, manuseio no processo produtivo e a disposição inadequada dos produtos pós-consumo;

- Os custos derivados de extração de matériasprimas escassos ou insumos importados;

- As leis ambientais, cada vez mais restritivas na utilização de materiais contaminantes perigosos, tanto nos países de origem quanto nos de destino (importadores);

- A imagem organizacional é afetada quando a organização causa impactos ambientais e constantemente busca utilizar matérias-primas virgens.

Tal postura acarreta danos à imagem organizacional (seta 1) em decorrência do aumento da consciência ecológica dos consumidores, da exposição na mídia do fator ambiental e do aumento dos custos (seta 2) das commodities, matérias-primas não renováveis e escassas.

A legislação (seta 3 ) em razão das pressões da sociedade tem restringido a utilização de matériasprimas virgens, contaminantes e perigosas, tanto no país de origem quanto nos de destino (importadores).

Além dos fatores motivadores principais, os fatores facilitadores para a implantação da logística reversa são:

- Envolvimento da alta administração e demonstração de sensibilidade com as questões ambientais;

- A existência e maturidade de um Sistema de Gestão Ambiental implantado, que tenha disseminado uma cultura ambiental e promovido uma capacitação das pessoas envolvidas no processo;

- A disponibilidade de investimentos, principalmente na fase inicial, com tendência de retorno em longo prazo (imagem organizacional) e curto prazo (econômico);

- Criação e manutenção de infraestrutura adequada com aquisição de máquinas, ferramentas, espaços e pessoas para o processo de logística reversa.

A existência de um Sistema de Gestão Ambiental maduro promove a sensibilidade dos agentes organizacionais em relação aos impactos ambientais (seta 4) e este sistema é mantido quando há o envolvimento da alta administração que considera prioritária as questões ambientais como o principal foco na imagem organizacional (seta 5) e, portanto, na manutenção e apoio do SGA (seta 6).

O envolvimento participante da alta administração também é responsável pela destinação dos recursos necessários para a implantação da logística reversa (seta 7) e criação da infraestrutura necessária para iniciar e manter o processo (seta 8).

Torna-se evidente que a organização levará em conta os custos de implantação do processo de logística reversa (seta 9) em comparação com os envolvidos na extração de matéria-prima virgem (seta 10) para a tomada de decisão de início e manutenção.

A operacionalização e manutenção da logística reversa dependem, sobremaneira, da manutenção da infraestrutura adequada e do desejo e envolvimento da alta administração.

\section{Método de Pesquisa}

Para a realização desta pesquisa foi utilizada a análise de dados qualitativa. A definição dessa abordagem considerou que na análise qualitativa existem descrições ricas que permitem que sejam preservados fluxos cronológicos, identificados achados inesperados e revistos modelos conceituais (MILES e HUBERMAN, 1994).

Yin (2001) ressalta que é o problema de pesquisa que determina 0 método e não o contrário, e via de regra, problemas do tipo "como" ou "por que" devem ser investigados por meio do método qualitativo. A pesquisa deste estudo busca entender quais fatores que influenciam e como agem na implantação do processo de logística reversa de microcomputadores pós-consumo.

\subsection{Procedimentos Metodológicos}

Yin (2001) classifica o estudo de caso em três tipos quanto ao objetivo da pesquisa: descritivo descreve o fenômeno em seu contexto; exploratório - trata com problemas pouco conhecidos, objetivando definir hipóteses ou proposições para futuras pesquisas; explanatório - possui o intuito de explicar relações de causa e efeito tendo como base uma teoria.

Este estudo tem o caráter descritivo, em que se verifica os fatores que influenciam a adoção da 
Lógica Reversa e exploratório, porque há poucos estudos empíricos no Brasil sobre a implantação desse tipo de Logística em processos industriais de microcomputadores.

A definição do número de casos e a seleção deles são fundamentais para o estudo de caso. $O$ objetivo de estudar um caso é para entendê-lo em profundidade e não para compreender outros casos ou realizar generalizações (EISENHARDT, 1989; YIN, 2001).

Para atender ao propósito desta pesquisa foram escolhidos dois casos, sendo um de uma empresa nacional e outra multinacional que produzem microcomputadores. Para a seleção das empresas foram considerados os seguintes critérios: as empresas deveriam ter implantado o processo de logística reversa em suas plantas industriais no Brasil; elas devem possibilitar e autorizar a entrevista com, pelo menos, um dirigente responsável pela implantação desse programa, um especialista nesse sistema, o gerente responsável pela operacionalização e um funcionário operacional da área.

\subsection{Procedimentos para a Coleta de Dados}

Segundo Yin (2001), princípio do uso de múltiplas fontes de evidência é uma característica dos estudos de caso que pode ajudar o investigador a abordar o caso de forma mais ampla e completa, além de facilitar o cruzamento de informações e evidências. Neste estudo, as técnicas de coleta de dados adotadas - a entrevista, a pesquisa documental, o registro em arquivos e a observação - foram selecionadas para responder a pergunta de pesquisa.

Foram analisados os seguintes documentos da empresa: Manual do Sistema de Gestão Ambiental; documentos de comunicação entre a empresa, objeto de estudo, e órgãos oficiais ambientais; planilhas de investimentos nas questões de logística reversa; fluxograma de operação da logística reversa; gráficos e tabelas de indicadores do processo; atas de reuniões pertinentes a implantação do processo de logística reversa; planilhas de aspectos e impactos ambientais; procedimentos para gestão de resíduos; ordens de serviço; documentos de controle de entrada de matérias-primas e do processo de produção; ciclo de aproveitamento dos resíduos.

Foram utilizados os seguintes registros em arquivos: as planilhas de controle de destinação de resíduos; os apontamentos da destinação dos produtos reciclados; material de treinamento, relatórios de status de projetos, e jornais informativos de circulação interna da empresa.

Outra fonte de evidência utilizada foram as entrevistas semiestruturadas. Segundo Flick (2004), a vantagem do uso consistente de um guia de entrevista é o aumento da comparabilidade dos dados levantados. A construção deste roteiro baseou-se, principalmente, nos pressupostos teóricos revisados na literatura e no modelo conceitual proposto, que auxiliarão na resposta da questão de pesquisa.

A entrevista foi realizada com o dirigente responsável pela implantação do processo de logística reversa na empresa. Com base na análise desses dados coletados foram desenvolvidos outros roteiros específicos para os outros níveis hierárquicos (especialistas ou gerente intermediário e funcionário operacional). As diferenças entre os roteiros devem-se ao tipo de contato e experiência que cada respondente teve com o programa. Por exemplo, os dirigentes tiveram mais contato com os fatores estratégicos e estão mais envolvidos com a tomada de decisão. Os especialistas relataram com mais detalhe as questões técnicas e metodológicas e os funcionários operacionais descreveram a sua participação nos projetos e no processo de comunicação do programa para toda a empresa.

Ao visitar o local de estudo foram realizadas observações e coletas de evidências sobre o caso em estudo. Para se aumentar a fidedignidade das observações foi desenvolvido um roteiro definido no protocolo. No caso das empresas do estudo, foram visitadas as áreas físicas envolvidas no processo de logística reversa, e realizadas observações dos processos relacionados com a atividade. Para este estudo de caso foram utilizadas as duas maneiras de observação direta: a formal que contemplou a participação em reuniões pertinentes aos assuntos da logística reversa, e a informal em que foi possível observar as áreas de armazenamentos de resíduos, a forma de manuseio de produtos e resíduos, as fontes poluidoras e o reaproveitamento dos resíduos sólidos.

Essas fontes de evidências possibilitaram o desenvolvimento de linhas convergentes de investigação, por meio de um processo de triangulação de informações de fontes de dados (YIN, 2001). Assim, a triangulação foi realizada com os resultados obtidos das entrevistas; da análise de documentos e dos registros em arquivos e observação direta referente ao processo de logística reversa. 


\subsection{Plano para Análise dos Dados}

Yin (2001) aponta que é necessário ter uma estratégia geral para a análise. "O objetivo final da análise é o de tratar as evidencias de forma adequada para se obter conclusões analíticas convincentes e eliminar interpretações alternativas".

Os modelos citados por Yin (2001) e utilizados neste estudo foram os seguintes: Padrão Combinado, que é a comparação de padrões com base empírica com os previstos; e Tabulação dos Eventos Significativos, com a utilização de categorias ou códigos.

Nessa análise serão observados os principais motivadores para a implantação do processo de logística reversa, e se podem ser considerados padrões para a indústria do setor. Serão também analisados os fatores que mantêm o processo em operacionalização.

Para facilitar o processo de manipulação e análise dos dados foi utilizado um software de análise de dados qualitativos, o Atlas-TI que possibilitou a importação tanto dos dados primários quanto dos secundários desta pesquisa. Os documentos e entrevistas foram importados diretamente para o software, que propicia a codificação de trechos de entrevistas e documentos, que remete o pesquisador do nível dos dados específicos do caso para o dos conceitos (BANDEIRA-DE-MELLO, 2006). Estes códigos facilitaram o processo de comparação, identificação das evidências dos fatores, além do estabelecimento de relações entre conceitos, visando o melhor entendimento e explicação do fenômeno estudado.

O produto final do processo de análise, conforme recomendação de Eisenhardt (1989), é a construção de um quadro descritivo do fenômeno estudado com base no estudo qualitativo, após a análise dos dados utilizando-se técnicas de codificação e categorização, a comparação com os pressupostos e evidências dos fatores identificados na literatura e, posteriormente, entre os dois casos.

\section{Resultados dos Estudos de Casos Comparativos}

Para analisar os projetos de logística reversa realizou-se um estudo de caso múltiplo em duas grandes empresas industriais na produção de computadores no Brasil uma nacional e outra multinacional de origem americana (EUA). Ambas possuem certificação ISO 14001:2000 e programas específicos de ecodesign e logística reversa de seus equipamentos pós-consumo.

\subsection{Caracterização da Empresa A}

A empresa nacional com planta industrial instalada na Região Metropolitana de São Paulo destinou 980 m2 para processamento de resíduos que é operado por cinco pessoas com capacidade de processar 850 toneladas/ano de materiais recicláveis. A empresa é $100 \%$ nacional com capital aberto e ações negociadas na Bolsa de Valores de São Paulo. Os produtos produzidos são direcionados ao mercado interno e externo (EUA e Europa).

Os principais produtos são: computadores, notebooks, PDA's, equipamentos de automação bancária e comercial e produtos high-end para áudio e vídeo. A empresa implantou um processo de reciclagem de microcomputadores pósconsumo. É entendido pela organização, como equipamento de pós-consumo os microcomputadores em obsolescência, ou seja, com idade de utilização entre 3 e 4 anos. Os fatores considerados para a obsolescência são: evolução tecnológica, mudança de atividade e desativação do equipamento.

\subsubsection{Resultados obtidos com o programa de logística reversa na empresa A}

A empresa decidiu implantar o processo de logística reversa em um centro de reciclagem própria porque não havia controle sobre o destino final dos resíduos quando os microcomputadores pós-consumo eram vendidos para empresas de reciclagem de terceiros. Tais empresas poderiam aproveitar os componentes de maior valor e descartar os componentes de baixo valor indevidamente no meio ambiente. A terceirização dessa etapa não isenta 0 fabricante da responsabilidade do impacto ambiental provocado pelo descarte em locais inapropriados, segundo o Sistema de Gestão Ambiental implantado pela empresa. O processo de reciclagem é segmentado nas seguintes fases: identificação; pesagem; desmontagem; segregação e destruição dos componentes; acondicionamento; pesagem; disposição; acompanhamento. Os recursos utilizados para o processamento são: bancadas, balança, ferramentas e prensas

Em 2003 foram reciclados 24,7 toneladas de componentes, na seguinte ordem como mostra a Figura 5. 
Figura 5 - Processamento de carcaças de computadores em 2003

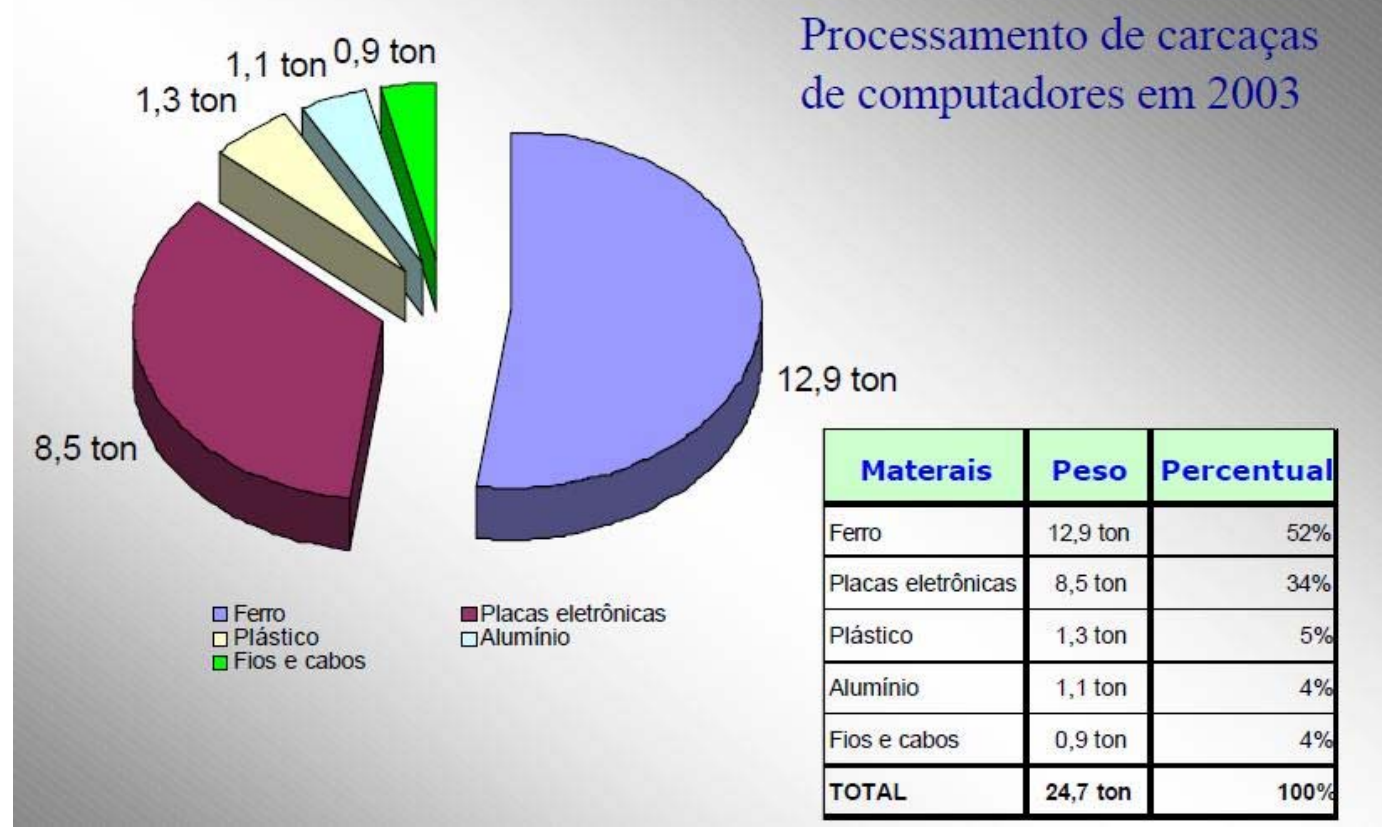

Fonte: Empresa A (2004).

Houve investimentos na infraestrutura na ordem de US\$170.000,00 em três anos, com o seguinte retorno para a operação: centralização de todas as atividades de utilidades e gestão ambiental; segregação adequada dos resíduos da operação; controle efetivo da disposição final dos resíduos; receita com a reciclagem de materiais na ordem de $\mathrm{R} \$ 195.000,00$ / ano. Parte da receita obtida com a reciclagem de materiais é aplicada em atividade de conscientização ambiental, projetos de incentivo a reciclagem e melhoria de gestão ambiental da empresa.

As atividades consideradas críticas para atendimento da diretiva européia são: levantamento de todos os componentes do equipamento (aproximadamente 4.000 itens) e identificação de quais deles não atendiam a norma de referência; verificação se os fornecedores possuíam capacidade para fornecimento adequado aos novos requisitos; desenvolvimento de novos fornecedores e alternativos. Implementação de novo processo produtivo; adequação da área de certificações com equipamentos que possam verificar a aderência ao atendimento da norma. Treinamentos específicos foram desenvolvidos para capacitar e desenvolver competências da equipe que desenvolve atividades que afetem a qualidade dos produtos isentos de substâncias nocivas, além de treinamentos específicos para identificar, utilizar e eliminar as substâncias nocivas.

A produção foi adequada para reduzir as substâncias nocivas e aumentar 0 índice de reciclagem, sem riscos à saúde e ao meio ambiente, tendo como referência a diretiva européia (RoHS). O Projeto exigiu mudanças na cadeia de suprimentos para garantir o fornecimento de partes e peças livres de substâncias nocivas, ou seja, Chumbo (Pb), Mercúrio (Hg), Cádmio (Cd), Cromo Hexavalente ( $\mathrm{Cr} 6+$ ), Bromobifenilas (PBB), Éteres de Bromobifenilas (PBDE). Estes materiais estão presentes nas placas eletrônicas, revestimentos, pinturas e partes metálicas.

\subsection{Caracterização da empresa B}

A empresa com sede nos Estados Unidos foi instalada no Brasil em novembro de 1999. Em 2007, a empresa expandiu sua atuação no país, com a instalação de mais uma planta. A empresa no Brasil produz notebooks, microcomputadores, servidores, concentradores de rede e sistemas de armazenamento impressoras, monitores de tela plana e projetores, televisores, produtos de rede e wireless, câmaras digitais, adaptadores de rede, e scanners.

Entre os clientes estão grandes empresas, governo, bem como pequenas e médias empresas e consumidores individuais. A empresa vende seus produtos e serviços diretamente aos clientes por meio de telefone, internet e outros canais indiretos de vendas.

A empresa é a segunda maior fabricante mundial de computadores pessoais e em 2008 nas 
regiões internacionais superou o faturamento nos EUA pela primeira vez, com Brasil, Rússia, Índia e China (BRIC) liderando o crescimento com expansão de 73 por cento no primeiro trimestre.

\subsubsection{Resultados obtidos com o programa de logística reversa da empresa B}

Os funcionários e prestadores de serviço contratados são treinados nos requisitos do ISO 14001, e muitos estão envolvidos em trabalhos para atender às metas ambientais departamentais. Outros cursos de treinamento são exigidos para certos grupos de funcionários, como o "Design for EHS", destinado a projetistas de produtos e engenheiros industriais. Além de treinamento, os funcionários têm a oportunidade de trabalhar e desenvolver projetos ambientais locais, como programas de transporte solidário.

Existe um programa de reciclagem, apenas para consumidores, que inclui a coleta gratuita de computadores da marca usados e de equipamentos periféricos em domicílio. O serviço não está vinculado à compra de um novo computador. Os consumidores que fornecerem um número de identificação de produto online recebem uma etiqueta de remessa pré-paga e podem agendar a coleta a domicílio do computador usado. Há mais de dois anos, a empresa também oferece a reciclagem gratuita de computadores e impressoras usadas de qualquer marca com a compra de um novo computador ou impressora da empresa. Para doar computadores que funcionam, a organização oferece aos clientes opções de apoio a organizações não-governamentais locais.

Nas instalações de manufatura, os funcionários da empresa procuram identificar soluções para reduzir a perda e aumentar a reciclagem. A empresa incorpora em seus contratos com os fornecedores de serviços de reciclagem um texto que se refere à legislação ambiental e exige que seus fornecedores cumpram todas as leis e requisitos municipais, estaduais, federais, regionais ou nacionais de qualquer tipo relativos ao gerenciamento adequado de materiais.

\section{Análise e Discussão dos Resultados}

O Quadro 2 apresenta os motivadores para a implantação da logística reversa nas duas empresas pesquisadas: impacto ambiental, recursos escassos, legislação, imagem institucional, infraestrutura, investimento, sistema de gestão ambiental e envolvimento da alta administração.
Os entrevistados das duas empresas têm consciência do impacto ambiental provocado pela produção de computadores, demonstrando conhecimento sobre as alternativas do setor para mitigar esse impacto.

Há preocupação específica com o consumo excessivo de recursos naturais. A empresa $A$ mostra resultados expressivos, com a reciclagem de $80 \%$ dos materiais usados na fabricação dos produtos, que retornam ao processo produtivo como matéria-prima secundária. Já a empresa $B$ reaproveita os computadores em programas de inclusão digital ou tem seus componentes e materiais desmanchados para a fabricação de outros produtos da empresa. Assim, a pesquisa corrobora com Stock (1998), Rogers e TibbenLembke (1999), Lacerda (2002) no que se refere ao papel da logística na devolução de produtos, redução, reutilização e reciclagem de materiais, substituição, conserto ou remanufatura de peças, componentes e materiais do pós-consumo, reduzindo os impactos ambientais do descarte e da extração da matéria-prima virgem.

A legislação foi apontada pela empresa B como um dos principais motivadores pelo fato de adequar os produtos ao mercado europeu, corroborando com as pesquisas desenvolvidas pelo RevLog (2009) que apontam a legislação ambiental como principal fator para adoção de programas de logística reversa. Por outro lado, para a empresa A, a legislação foi um entrave no início da realização do programa, pelo fato de cobrar uma série de impostos sobre os equipamentos recolhidos dos usuários e sobre a destinação do material residual.

Para as duas empresas, a logística reversa oferece a oportunidade de melhoria da imagem organizacional. Para a empresa A o programa de logística reversa já foi divulgado espontaneamente na mídia televisiva e a área de marketing utiliza um programa como um diferencial para seus clientes. Da mesma forma, o programa fortalece a posição da empresa B com seus clientes pela preocupação ambiental. O grupo Revlog (2009) também aponta a crescente conscientização ambiental dos consumidores como um dos fatores para a adoção de programas dessa natureza.

A infraestrutura dos programas de logística reversa da empresa $A$ foi desenvolvida no início para atender as empresas do grupo e se estendeu para o atendimento de clientes corporativos e domésticos, com a formação de 23 profissionais na área. Além disso, buscou atender a leis estaduais específicas nesse quesito. Na empresa B foram criados dois centros de reciclagem nas regiões sul e sudeste, também para atender aos clientes. 
Quadro 2 - Motivadores da Logística Reversa

\begin{tabular}{|c|c|c|}
\hline Motivadores & Empresa A & Empresa B \\
\hline Impacto Ambiental & $\begin{array}{l}\text { A produção de um computador emite cerca de } 1300 \\
\text { kg de CO2; } \\
\text { Nos últimos } 40 \text { anos atingiu-se o ponto de } \\
\text { equilíbrio, e no ano passado foi ultrapassado em } \\
25 \% \text { a relação do consumo x capacidade de } \\
\text { recomposição dos recursos naturais consumidos. }\end{array}$ & $\begin{array}{l}\text { Há uma meta de recuperar } 125 \text { mil toneladas em } \\
\text { equipamentos até } 2009 \text { em todo o mundo. Em } 2006 \\
\text { foram reciclados mais de } 35 \text { mil toneladas de } \\
\text { equipamentos, um salto de } 93 \% \text { sobre o montante } \\
\text { reciclado no ano anterior. }\end{array}$ \\
\hline $\begin{array}{l}\text { Recursos } \\
\text { Escassos }\end{array}$ & $\begin{array}{l}\text { São reciclados mais de } 80 \% \text { das } 1,2 \text { mil toneladas } \\
\text { de materiais usados na fabricação dos produtos, } \\
\text { que retornam para o início da cadeia produtiva. }\end{array}$ & $\begin{array}{l}\text { A empresa avalia o estado das máquinas, } \\
\text { recondiciona o equipamento e depois o envia para } \\
\text { ONGs que fazem o trabalho de inclusão digital ou } \\
\text { tem seus componentes e materiais desmanchados } \\
\text { e reaproveitados na fabricação de outros produtos } \\
\text { da empresa. }\end{array}$ \\
\hline Legislação & $\begin{array}{l}\text { Ainda faltam leis que padronizem os processos de } \\
\text { acompanhamento dos equipamentos de } \\
\text { informática, desde a sua produção até o seu } \\
\text { descarte. } \\
\text { Isso fez com que, no início, a empresa tivesse que } \\
\text { pagar uma série de impostos sobre os } \\
\text { equipamentos recolhidos dos usuários e sobre a } \\
\text { destinação do material residual. A empresa teve de } \\
\text { conscientizar os órgãos governamentais para que } \\
\text { estes impostos não fossem mais cobrados. }\end{array}$ & $\begin{array}{l}\text { A empresa atende as diferentes leis e regulamentos } \\
\text { ambientais nos países em que produz e } \\
\text { comercializa seus equipamentos. } \\
\text { Atende as diretrizes europeias - Restriction of } \\
\text { Certain Hazardous Substances (RoHS) e Waste } \\
\text { from Electrical and Electronic Equipment (WEEE), } \\
\text { Lixo Vindo de Produtos Eletroeletrônicos e as } \\
\text { legislações "lead free" (solda sem chumbo) de } \\
\text { alguns estados americanos e Japão entre outras. }\end{array}$ \\
\hline $\begin{array}{l}\text { Imagem } \\
\text { Organizacional }\end{array}$ & $\begin{array}{l}\text { A empresa está colhendo bons resultados do seu } \\
\text { sistema de gestão ambiental, adotado em } 2001 . \\
\text { O programa já foi divulgado espontaneamente na } \\
\text { mídia televisa e hoje a área de marketing divulga o } \\
\text { programa como um diferencial para seus clientes. }\end{array}$ & $\begin{array}{l}\text { Além de melhorar a imagem da empresa perante o } \\
\text { público, o programa fortalece a posição com } \\
\text { clientes que escolhem negociar por causa da } \\
\text { preocupação ambiental. }\end{array}$ \\
\hline Infraestrutura & $\begin{array}{l}\text { Inicialmente para atender a própria empresa e } \\
\text { empresas do grupo. Hoje no atendimento de } \\
\text { clientes corporativos, domésticos e na demanda do } \\
\text { atendimento das leis estaduais que versam sobre o } \\
\text { assunto, o projeto esta sendo revisto. } \\
\text { Foram formados } 23 \text { profissionais especialistas na } \\
\text { área ( } 5 \text { na reciclagem). }\end{array}$ & $\begin{array}{l}\text { Dois centros de reciclagem, nas regiões Sudeste e } \\
\text { Sul do Brasil. O consumidor entra em contato com a } \\
\text { empresa por meio de um site e tem seu computador } \\
\text { recolhido, sem custo. A empresa avalia o estado } \\
\text { das máquinas, recondiciona o equipamento e } \\
\text { depois o envia para ONGs que façam trabalhos } \\
\text { relevantes de inclusão digital }\end{array}$ \\
\hline Investimentos & $\begin{array}{l}\text { Foram investidos } \mathrm{R} \$ 350 \text { mil na construção de um } \\
\text { centro de reciclagem com uma área de } 750 \mathrm{~m}^{2} \text {. }\end{array}$ & Os valores investidos não foram divulgados. \\
\hline $\begin{array}{l}\text { Sistema de } \\
\text { Gestão Ambiental }\end{array}$ & $\begin{array}{l}\text { Com a abertura do mercado brasileiro de } \\
\text { tecnologia, o tema meio ambiente ganhou força no } \\
\text { início da década de } 1990, \text { começou uma discussão } \\
\text { sobre resíduos sólidos no Brasil, e também } \\
\text { surgiram as normas de meio ambiente da série ISO } \\
14000 .\end{array}$ & $\begin{array}{l}\text { A visão da empresa é criar uma cultura em que a } \\
\text { excelência ambiental seja uma segunda natureza. A } \\
\text { missão é integrar plenamente o manejo ambiental } \\
\text { na atividade de fornecimento de produtos com } \\
\text { qualidade e pelo melhor valor. Expectativas de } \\
\text { excelência ambiental em toda a cadeia de } \\
\text { suprimentos. }\end{array}$ \\
\hline $\begin{array}{l}\text { Envolvimento da } \\
\text { alta administração }\end{array}$ & $\begin{array}{l}\text { As áreas que suportam a Logística Reversa estão } \\
\text { subordinadas ao Comitê de Gestão Ambiental que } \\
\text { é composto pelo presidente e diretores do grupo. } \\
\text { Este Comitê foi o idealizador e tem deixado indícios } \\
\text { claros na sua manutenção. }\end{array}$ & $\begin{array}{l}\text { O objetivo da alta administração é levar a } \\
\text { organização a ser a maior empresa de tecnologia } \\
\text { do mundo e fazer diferença significativa para } \\
\text { proteger o planeta. } \\
\text { Contratação de um vice-presidente gerenciar } \\
\text { compromissos ambientais e sociais reforçando os } \\
\text { programas de responsabilidade corporativa. }\end{array}$ \\
\hline
\end{tabular}

Fonte: Dados da pesquisa

A realização de programas de logística reversa para microcomputadores requer processos complexos e exigem investimentos. A empresa $A$ divulga valores na ordem de $\mathrm{R} \$ 350$ mil na construção de um centro de reciclagem, enquanto a empresa B afirma que realizou investimento, mas não divulga valores. Para ambas as empresas, o retorno financeiro do programa ainda não foi dimensionado, em razão das recentes iniciativas da implantação da logística reversa nas empresas estudadas. Portanto, neste item, não é possível corroborar com as conclusões de Revlog (2009), Rogers; Tibben-Lembke (1999) sobre os benefícios econômicos da matéria-prima secundária que retorna ao processo produtivo, reduzindo custos com o descarte seguro dos resíduos.

A continuidade do programa ocorre principalmente pelas exigências dos clientes corporativos e empresas estatais, além da necessidade de manter a certificação do Sistema de Gestão Ambiental.

O envolvimento da alta administração nas questões ambientais é imprescindível para a manutenção e continuidade dos programas de logística reversa. As duas empresas mostraram o 
comprometimento de diretores e presidentes com os programas e outros projetos socioambientais.

\section{Considerações Finais}

O objetivo da pesquisa foi alcançado na medida em que foram identificados, nas empresas pesquisadas, os fatores motivadores para a implantação da logística reversa para microcomputadores e que contribuem para a sua manutenção. A exigência de grandes investimentos no programa, com incertezas de retorno e falta de incentivo fiscal são preocupações que restringem a aplicação desse processo, principalmente nas empresas nacionais.

A pesquisa permitiu identificar os objetivos estratégicos mais relevantes para a implantação da logística reversa para os microcomputadores. O primeiro é atender a legislação e normas dos mercados e países consumidores dos produtos e aos requisitos internos do Sistema de Gestão Ambiental implantado. Outros objetivos estratégicos determinantes identificados foram a imagem institucional, que busca vantagens competitivas pela diferenciação que a logística reversa incorpora aos produtos.

O mecanismo utilizado para incentivar a logística reversa junto aos consumidores não segue um padrão definido, a empresa " $A$ " se compromete a retirar equipamentos de qualquer fabricante, desde que o cliente adquira um novo produto da marca. Já a empresa B assume o compromisso de somente retirar equipamentos de sua marca, mas sem a necessidade de o cliente se comprometer em adquirir um produto novo.

Outras discussões não abordadas na literatura são o custo de implantação e manutenção da logística reversa e quais são as possibilidades de retorno econômico na aplicação do modelo que, devidamente quantificados, podem agir como motivadores da implantação do programa. Nesse estudo, como os programas são recentes, não houve ainda retorno do capital inicial investido.

Um das principais limitações desse estudo foi 0 fato de que as informações levantadas nas duas empresas não apresentaram um padrão, uma especificou de forma detalhada alguns motivadores da logística reversa, enquanto a outra detalhou outros motivadores. Isso dificultou uma comparação mais precisa dos casos estudados.

Constatou-se, além disso, durante a pesquisa, que vários aspectos da logística reversa para microcomputadores não são abordados na literatura consultada, como as principais leis, normas ambientais referentes à destinação de equipamentos de informática e modelos que estabeleçam a vida útil e qual a destinação que os consumidores dão aos microcomputadores ao final de sua vida útil. Isso sugere um vasto campo para o desenvolvimento de pesquisas nessa área.

Para futuros estudos recomendam-se pesquisas para aprofundar o conhecimento dos programas de logística reversa das empresas usuárias de microcomputadores, buscando verificar principalmente os seguintes elementos: identificar o tempo médio de vida útil dos microcomputadores entre as empresas usuárias; verificar o destino final dos equipamentos no fim da vida útil; comparar os diferentes modelos de logística reversa aplicados aos equipamentos de informática e o respectivo retorno à imagem organizacional; avaliar o desempenho financeiro desses programas; estimar a contribuição da logística reversa para mitigar o impacto ambiental da disposição final desses resíduos.

\section{Referências}

BANDEIRA-DE-MELLO, R. Softwares em pesquisa qualitativa. In: GODOI, C. K.; BANDEIRA-DEMELLO, R.; SILVA, A. B. (Orgs.). Pesquisa qualitativa em estudos organizacionais: paradigmas, estratégias e métodos. São Paulo: Saraiva, 2006.

BRASIL. Decreto n 875, de 19 de Julho de 1993. Promulga o texto da convenção sobre o controle de movimentos transfronteiriços de resíduos perigosos e seu depósito. Disponível em: <

http://www.planalto.gov.br/ccivil_03/Decreto/D0875. htm>. Acesso em 04/05/2009.

EISENHARDT, K. M. Building theories from case study research. Academy of Management

Review, v. 14, n. 4, p. 522-550, Oct. 1989.

FLEURY, P. F. Logística empresarial: a perspectiva brasileira. São Paulo: Atlas, 2000.

\section{FLICK, U. Uma introdução à pesquisa} qualitativa. 2. ed. Porto Alegre: Bookman. 2004.

ITDATA, Consultoria, Press Releases sobre Mercado de PCs no Brasil - 2006. Disponível em: < http://www.itdata.com.br/prs/index.php?location=prs \&id=04>. Acesso em 02/03/2009.

LACERDA, L. Logística reversa: uma visão sobre os conceitos básicos e as práticas operacionais. Rio de Janeiro: COPPEAD, 2002. Disponível em: $<$ http://www.centrodelogistica.org/new/fspublic.htm>. Acesso em: 07 Jul. 07.

LEITE, P. R. Logística reversa: meio ambiente e competitividade. São Paulo: Prentice Hall, 2003. 
Canais de distribuição reversos. Revista

Tecnologística, v. 6, n. 61, p. 46-67, dez. 2004.

. Logística reversa: categorias e práticas empresariais em programas implementados no

Brasil - um ensaio de categorização. In:

ENCONTRO ANUAL DA ASSOCIAÇÃO DOS

PROGRAMAS DE PÓS-GRADUAÇÃ̃O EM

ADMINISTRAÇÃO, 29., 2005, Brasília. Anais... Rio de Janeiro: ANPAD, 2005.

MATTHEWS S,; MATTEWS D. Information Technology Products and the Environment. In Kuehr, Ruediger; Eric Williams: Computers and the Environment: Understanding and Managing Their Impacts, Kluwer Academic Publishers, EcoEfficiency in Industry and Science Series, Dordrecht/NL, October 2003

MILES, M. B., HUBERMAN, A. M. Qualitative data analysis: an expanded sourcebook. 2 ed.

Thousand Oaks: Sage, 1994.

REVLOG. Pesquisa geral no site. Disponível em: <http://www.fbk.eur.nl/OZ/REVLOG/>. Acesso em: 02 mar. 2009.

ROGERS, D. S.; TIBBEN-LEMBKE, R. S. Going backwards: reverse logistics, trends and practices. Reno: Center for Logistics Management, 1999.

SECRETARIA DO MEIO AMBIENTE. Convenção da Basiléia sobre o controle de movimentos transfronteiriços de resíduos perigosos e seu depósito. 2. ed. São Paulo: Secretaria do Meio Ambiente, 1997.

STOCK, J. R. Development and implementation of reverse logistics programs. Oak Brook: Council of Logistics Management, 1998.

YIN, R. K. Estudo de caso: planejamento e métodos. 2. ed. Porto Alegre: Bookman, 2001. 